\title{
TURISMO E MEIO AMBIENTE Identificação e Possibilidades da Oferta Alternativa
}

\author{
Olga Tulik*
}

\begin{abstract}
RESUMO: O Turismo, frente à questão ambiental. apresenta amplas possibilidades que vem sendo divulgadas pelos meios de comunicação. Este artigo considera a oferta alternativa, do ponto de vista geográfico, identificando a variedade de formas, conceitos e interferências no meio ambiente.
\end{abstract}

UNITERMOS: Turismo: meio ambiente: geogratia; oferta alternativa; atividades recreacionais.

ABSTRACT: The Tourism, in face of the emironmental concem, presents great possibilites that have been spreading by the communication media. This article attends to the altenative supph' in Geography's point of view, identifying the varicty if wavs, concepts and interferences in the environment.

KEY WORDS: Tourism: environment; geography; altenative supply; recreational activitics.

\section{MEIO AMBIENTE, GEOGRAFIA E TURISMO: O APELO DA PROPAGANDA}

A diversidade das características geográficas tem norteado a seleção de localidades e de roteiros turísticos. Este fato não é recente e vem ocorrendo desde os tempos antigos quando o turismo e muitas das atividades de recreação e de lazer eram escolhidas e sustentadas pelos atributos geográficos do meio ambiente.

$\left({ }^{*}\right)$ Doutor em Ciências Humanas. Prolessor Assistente Doutor do Curso de Turismo do Departamento de Relaçōes Públicas. Propaganda e Turismo da ECA J JSP.

End. para corresp.: Rua Conde de Irajá. 184. apto. 224 - CEP 04118 - São Paulo - SP - Brasil. 
O turismo atual, fortemente influenciado pela imagem que, a nível concreto, é transmitida pelos meios de comunicação, privilegia o meio ambiente na difusão das destinações e produtos turísticos. A aceitação desta imagem viu-se favorecida pela preocupação com as questões ambientais que a nível mundial se acentuou na década de 1970 e, mais ainda, na de 1980, em razão de conhecidas implicações ecológicas de certas atividades humanas. Além disso, vários outros fatores, como a necessidade de descanso físico, a vontade de conhecer novos lugares e de fugir dos grandes centros urbanos ${ }^{1}$, concorrem para o desejo geral de evasão.

A atual conotação do vocábulo férias é outro fato que deve ser considerado na relação turismo-meio ambiente. Conforme lembra Michaud, a palavra férias esteve no passado associada à noção de repouso e recuperação, enquanto que agora se propaga o seu aproveitamento máximo através de atividades físicas, induzindo ao "lazer ativo", à descoberta, à aventura e ao conhecimento da variedade e riqueza cultural e natural ${ }^{2}$. A preocupação com a saúde, o culto ao corpo e ao sol permeiam as múltiplas atividades desenvolvidas para ocupar o tempo livre em contato com o meio ambiente.

A propaganda turística reflete esta nova ótica da utilização dos períodos de tempo livre dirigida para as mais variadas práticas de atividades de recreação e de lazer. Este é, na verdade, um aspecto marginal das questôes relacionadas ao meio ambiente e que, muitas vezes, se traduz apenas pela simples colocação de um qualificativo às práticas que já vinham sendo realizadas e que assumem o rótulo "ecológico".

Estes casos evidenciam a exploração econômica, pura e simples, de um veio rico de uma temática atual e emergente que, certamente, não será tratado com o respeito e a consideração devidos à causa ambiental. Felizmente a este aspecto negativo contrapõem-se o positivo, pois é fato sabido e reconhecido que a propaganda e os modismos também podem favorecer determinadas áreas contribuindo para revelar seus atributos e para impulsionar seu desenvolvimento turístico.

Os meios de comunicação registram casos de turistas que, estimulados pelas imagens de filmes, novelas, televisão e obras literárias, descobrem regiões que até então permaneciam esquecidas ou pouco procuradas. Foi o que aconteceu com o sul da Escócia, valorizado graças ao filme "Robin Hood - o príncipe dos ladrões", que passou a atrair os turistas que antes preferiam permanecer ao norte do país (entre Edimburgo, Glasgow e as Terras Altas) ${ }^{3}$. Da mesma maneira, mas através de novelas de televisão, foram difundidas imagens do Pantanal Matogrossense e da Chapada Diamantina, regiões até então não alcançadas pelos roteiros turísticos. Entre as obras literárias registra-se por exemplo, a difusão de Ilhéus (Bahia) através do romance de Jorge
Amado, "Gabriela, Cravo e Canela", posteriormente transformado em novela de televisão e em filme. Outro caso corresponde à obra de José de Alencar, "Iracema que morreu de tristeza e de saudade nas areias de Mucuripe" (Ceará) $)^{4}$.

Paralelamente à esta promoção de imagens veiculadas pelos meios de comunicação que despertam o interesse do turista induzindo fluxos, outras localidades (consagradas ou não como núcleos receptores e até mesmo como pólos turísticos) reivindicam sua fatia neste imenso espaço mercadológico voltado para o meio ambiente e, em especial para o "ecológico".

Os exemplos são numerosos e nem é preciso ir muito além do território brasileiro: Ibitinga (São Paulo), conhecida como "Capital dos Bordados”, almeja explorar, também, seu 'potencial ecológico' representado por um imenso lago de barragem formado pela usina de Ibitinga no rio Tietê e pela flora e fauna dos rios Jacaré Pepira e Jacaré Guaçu'; Foz do Iguaçu (Paraná), por exemplo, já vem explorando, além do Ecomuseu, o roteiro denominado "Macuco Safari" através do qual o turista percorre uma trilha e se coloca em contato com a natureza ${ }^{6}$; Joinville (Santa Catarina), tradicionalmente conhecida pelas manifestações culturais da colonização alemã e pelas suas indústrias, já propaga sua nova imagem como "endereço certo para os adeptos do turismo ecológico"; no interior de São paulo, o município de Cabreúva revela-se como "opção ecológica";; enquanto Pariquera-Açu, no Vale do Ribeira, para o qual "o turismo ecológico é a esperança" quer promover suas riquezas naturais situadas na Mata Atlântica9.

\section{VARIEDADE DE CONCEITOS DE TURISMO FRENTE À QUESTÃO AMBIENTAL}

O turismo organizado sempre apresentou, e continua apresentando, destinos exclusivos e roteiros pré-estabelecidos que incluem uma grande variedade de modos de viajar e de permanecer num certo local, dirigidos tanto para o descanso como para a prática de múltiplas atividades de recreação e de lazer, porém sempre apoiadas nas condições naturais e culturais,

No contexto atual, em que o meio ambiente assume cada vez maior importância na venda do produto turístico, uma razoável parcela da propaganda concentra-se em propostas de alternativas de excursionismo e de turismo que recebem várias denominações: turismo verde, turismo de aventura e, principalmente, turismo ecológico ou ecoturismo com os seus desdobramentos criativos (como é o caso de "ecosselvagem"10 ou "turismo selvagem" e outros tantos neologismos). 
De um modo geral, os termos se confundem, revelando conceituação imprecisa. Seus adeptos e promotores divulgam, freqüentemente, a conotação com a natureza, com a preservação e utilização consciente do meio ambiente. Algumas frases colhidas em jornais de São Paulo (Cadernos de Turismo) podem confirmar estas idéias:

...E a onda do ecoturismo que dia a dia recruta noros adeptos, haja rista a franca expansão dos roteiros que exaltam a naturcza. ${ }^{11}$

No contraponto de todas estas manifestaçòes da natureza...vainos encontrar também...as expressöes da criação humana... ${ }^{2}$

As belezas naturais da regiäo desfilam potencialidades ao turismo ecológico... ${ }^{1.3}$

Até que ponto está correto vincular o ecoturismo apenas às condições naturais? Não se estaria, desta forma, negando o próprio sentido do radical ECO, originário de "OIKOS" (grego) significando "casa" e, por extensão ambiente?

Tratando do tema "O termalismo: um turismo ecológico?", Michaud observa, em relação a França, que o climatismo na montanha, o termalismo na média montanha e a talassoterapia em algumas praias constituem formas de exploração turística de recursos naturais, particularmente determinados pelo meio geográfico e pelas condiçōes ecológicas. $^{2}$

A oferta de produtos turísticos similares divulgada no Brasil pelos meios de comunicação apresenta-se extremamente rica, muito embora nem sempre apareça como "ecológica".

Raramente o "ecoturismo" indica sua conceituação mais ampla, e porque não dizer mais correta, envolvendo o significado pleno do termo ECO como ocorre nestes exemplos: "Encravada entre a serra e o mar, Joinville é um endereço certo para os adeptos do turismo ecológico. Sua beleza natural...museus que conservam o mais rico acervo da colonização alemã no Brasil...A arquitetura em estilo enxaimel..."? Em relação à Chapada Diamantina que vem sendo denominada "Estrela do Turismo Alternativo" 14 , é interessante observar que, embora tenha sua oferta apoiada no patrimônio natural e cultual, não há referência ao "ecológico", mas ao turismo de aventura.

Ainda com referência a este sentido amplo, outras possibillidades de turismo alternativo já vêm sendo praticadas no exterior. Na GrãBretanha, por exemplo, os ônibus-corrreio ("post bus") que fazem a entrega de correspondência em lugares distantes estão à disposição daqueles que desejarem utilizá-los. Considerado de baixo custo, este "serviço prestado ao turismo visa mais a divulgação de regiões pouco conhecidas da Grã-Bretanha do que auferir lucros"15.
Estas formas de turismo alternativo e as conseqüentes atividades que se expandiram a partir de "onda ecológica", ainda se mantém relacionadas às três funções básicas do turismo: deslocamento, hospedagem e atividades de lazer. Este fato demonstra que o turismo não mudou, apenas foi adaptado à nova mentalidade em relação à causa ambiental servindo, em alguns casos, como chamariz de venda.

Todavia, é inegável a força do turismo ecológico ou "ecoturismo" - neologismo que vem se firmando, assim como tantos outros criados na esteira da onda ambientalista e dos quais derivam inúmeras atividades ligadas ao meio ambiente.

\section{ALTERNATIVAS DAS ATIVIDADES TURÍSTICAS}

O turismo alternativo frente ao meio ambiente aprimorou-se na oferta de atividades diversificadas quanto à forma, aos alojamentos e equipamentos utilizados, desafiando a criatividade de seus promotores, atiçando o apetite dos praticantes e estimulando a propaganda e o desenvolvimento de programas ecológicos por parte de comunidades e governantes de áreas carentes em recursos financeiros, que buscam uma saída para seus problemas econômicos.

A oferta de equipamentos para atividades esportivas e de recreação terrestre, aquática e aérea é, de um modo geral, muito diversificada no que se refere ao turismo litorâneo, lacustre e fluvial, e seu uso estendeu-se, também, às propostas de turismo alternativo. Em princípio, a oferta inclui desde os mais simples equipamentos, sobejamente conhecidos e utilizados, até outros, mais sofisticados, acessíveis a uma minoria que os utiliza, às vezes, mantendo sua denominação original por falta do termo correspondente no vernáculo. Entre eles estão bicicletas, motocicletas, jipes e "bugs"; canoas, barcos (à vela, remo e motor), lanchas de passeio com ou sem esquís, lanchas de corrida ("trimarã"), caiaques, botes infláveis para águas calmas ("banana boat") e para descer corredeiras, bóias gigantes com cadeiras individuais para rios de águas turbulentas ("tanganyika tidal") ${ }^{16}$, embarcações especiais para locomoção em terrenos pantanosos ("airboat"), "jet skis", pranchas para "surf" e "windsurf"; asas deltas, ultra-leves e balões.

Como não poderia deixar de acontecer, nem todas as atividades estão ao alcance do público em geral. O seu conjunto inclui não só aquelas que podem ser praticadas por todos, indistintamente, como também outras destinadas a grupos específicos quanto às faixas etárias que segmentam determinadas ofertas; quanto às condições físicas, que devem ser razoáveis para atividades mais audaciosas; e quanto às condições financeiras, que devem ser suficientes para arcar com os custos. 
Assim, a oferta de atividades terrestres, aquáticas, aéreas e subterrâneas (isoladas ou associadas) desfilam nos jornais especializados em turismo, demonstrando uma grande variedade de opçōes que parecem estar a caminho de seu apogeu.

As atividades terrestres incluem desde a simples contemplação de áreas com qualidades cênicas, a observaçāo da fauna (inclusive de aves e de seus ninhais) e da flora de um modo geral, até a participaçāo ativa.

A essência da prática terrestre é o "trekking" por trilhas e picadas abertas em meio a diferentes tipos de matas, ou por trilhas recuperadas mas que já vêm alcançando os caminhos históricos. Caminhadas, montanhismo e alpinismo, além de "escalaminhadas"* sāo atividades de "trilheiros" e "mochileiros". Aparecem algumas opçōes de trilhas monitoradas ou, para aqueles que querem seguir seu próprio rítmo, trilhas autoguiadas. "É um contingente de andarilhos almejando contato íntimo com a natureza, ávidos pelo ecoturismo, em meio a rios, grutas, vales, morros, cachoeiras cavernas e outros recantos naturais" 18 .

Além de "safaris fotográficos" e de passeios de jegue, de cavalo e de charrete, os praticantes tem a sua disposiçāo passeios de jipe e de "bugs" que se desenvolvem nas praias de areias firmes, nas dunas, nas montanhas, matas e desertos floridos.

As atividades aquáticas e aéreas, sempre objetivando desfrutar a natureza, mostram uma variedade muito grande: passeios de barcos e de escunas, "focagem" de jacarés, canoagem (praticada em águas turbulentas), canoagem "turística" ou canoada (praticada em águas calma), "cannyon in"**, mergulho recreativo (praticado sem pesca e sem ancoragem) e "snorkeling" (com equipamento).

Geralmente associadas às atividades terrestres e às aquáticas aparecem atividades subterrâneas como a exploraçāo de grutas e cavernas.

Aproveitando a "onda ecológica", a oferta de produtos turísticos cresceu e diversificou-se alcançando a especializaçāo através da promoçāo de pacotes e roteiros para públicos específicos: acampamentos para crianças e adolescentes ${ }^{211}$ quase sempre localizados em fazendas $c$ sítios com grandes áreas verdes e oferecendo atividades rurais e ecoló gicas ${ }^{21}$; redes de "campings" especializados em funçāo de equipamen-

${ }^{*}{ }^{*}$ Escalaminhada: neologismo usado pelos trillheiros para fundir as práticas do "trek king" e alpinismo moderado.

(**) "Cannyon in": modalidade de turismo cm cachoeira. cada vez mais praticadia pelos adeptos do "trakking". Consiste em descer. com duas cordas de segurança. por dentro da cachoeira. tos específicos e que atendem crianças a partir de dois anos de idade ${ }^{21}$ SPAs, para aqueles que desejam dedicar-se à saúde e ao bem estar físico e mental mas, principalmente, ao emagrecimento, criando uma nova categoria de turista - o "diet Hóspede"22; hotéis-fazenda que promovem "lazer em cenário ecológico com atividades na horta e pomar²3"; hotéis de lazer ("resorts") que aliam atividades físicas ao conforto moderno.

Nessa "onda ecológica" florescem ofertas que procuram captar segmentos intelectualizados oferecendo excursōes ecológicas e expediçōes científicas com acompanhamento de especialistas (arqueólogos, biólogos, geógrafos e geólogos). Como expediçāo ecológica foi divulgada uma viagem do Brasil para a ilhas Galápagos (Equador), pretendendo ser "mais do que um simples roteiro turístico"24. Da mesma maneira a Universidade da California está permitindo a participaçāo de leigos em expediçōes científicas que, na ocasiāo, estavam programadas em torno de escavaçōes arqueológicas e viagens para a pesquisa de ervas medicinais, sendo que um porta-voz advertiu tratar-se de "uma pesquisa real e nāo de um simples tour para turistas entediados" 25 .

A divulgaçāo ultrapassa a oferta de destinaçōes e chega à prestaçāo de serviços especializados aos "campings", hotéis-fazenda chalés e pousadas e, também, à área educacional através da promoçāo de cursos de espeleologia, hipismo rural, mergulho autônomo e recreacional, canoagem, esqui aquático, "rafting", enologia e tantos outros.

\section{TURISMO E MEIO AMBIENTE: CONVIVENCIA AGRESSIVA OU COEXISTÊNCIA PACÍFICA?}

O impacto ambiental do turismo, reconhecidamente inferior àquele provocado por outras atividades humanas, é um assunto polêmico e ainda pouco estudado. Divulgado por muitos como atividade nāo-poluidora, o turismo apresenta, entretanto, muitos efeitos diretos e indiretos que acabam provocando impactos econômicos, físicos e sociais $^{2 n}$. Os estudos realizados apontam malefícios e benefícios, além de possibilidades de convivência harmoniosa ${ }^{27}$.

Estas consideraçōes também se aplicam ao turismo alternativo, no qual se destaca o "ecoturismo" que, embora possa parecer paradoxal, pode gerar danos ao meio ambiente. A propagaçāo do turismo de aventura, do "ecoturismo" e de outras formas alternativas que têm como base a exploraçāo do meio ambiente natural, pode provocar impactos pouco perceptíveis aos governantes pela sua difusāo em áreas novas, sem infra-estrutura ou mesmo despovoadas. Exceçāo feita às áreas de preservaçāo ambiental que têm controle ofical e regular, os 
danos nem sempre são visíveis escapando aos proprios praticantes, muitos dos quais ecologistas convictos. Isto acontece porque grande parte dos efeitos diretos sequer são vistos e quando isso ocorre, exigem providências a médio e longo prazo. Ao contrário, outros são facilmente localizados, como o lixo acumulado em locais inadequados e a perturbação da tranqüilidade devido à concentração de muitas pessoas num mesmo lugar e ao mesmo tempo.

Algumas pesquisas relatadas por Cole, referentes aos Estados Unidos,mostram perturbações ambientais provocadas pelos efeitos de caminhadas ou por veículos (bicicletas, jipes e motocicletas) em áreas de acampamentos, de trilhas e onde foram praticadas outras atividades recreacionais. São assinalados, também, conflitos com atividades nãorecreacionais (ecológicas, científicas e paisagísticas); deterioração do local reduzindo sua atratividade; impactos, principalmente no que se refere ao solo (compactação e erosão), à vegetação (redução de espécies e extinção de sinusias), às águas (por contaminação) e aos animais (dispersão e redução do número). ${ }^{28}$

As pesquisas mostram, além disso, que o impacto é maior no primeiro momento da ocupação e que a recuperação, neste caso, é mais lenta do que nas utilizações posteriores; que a área de ocorrência destes impactos está mais concentrada em acampamentos e trilhas; que o impacto nos recursos móveis (águas e animais) podem ser mais extensos do que aqueles causados à vegetação e ao solo; e, finalmente, que em razão de condições geográficas específicas de determinadas áreas, há uma grande variedade de impactos físicos diretamente relacionados com a escala de utilização destes recursos e com o número de pessoas envolvidas $^{28}$.

É possível uma coexistência pacífica? Algumas referências positivas mostram esta possibilidade. Para isso, convém, no que se refere ao turismo alternativo, conhecer sua intensidade, fator fundamental para o entendimento do seu dinamismo e da sua força de atuação; sua densidade e, além disso, seu limite de tolerância e capacidade de carga recreacional para evitar danos ao meio ambiente.

De qualquer modo, a introdução de atividades alternativas numa área deverá ser gradual e progressiva, e será tanto mais efetiva quanto mais estiver associada aos interesses dos dirigentes locais e da comunidade como um todo, incluindo seus praticantes e aqueles que promovem tais alternativas.

Todavia, a conscientização ambiental dos praticantes desempenha papel importante e seria muito proveitoso se todos cumprissem o lema dos espeleólogos: "Da mata nada se tira, a não ser fotos, e nada se deixa, a não ser pegadas".
Convém ressaltar mais uma vez que são muitas as possibilidades do turismo alternativo capazes de se sobrepor aos modismos. É preciso conhecer melhor como reage o meio ambiente frente às açōes desencadeadas pelo turismo e por suas diferentes formas alternativas o que, sem dúvida, merece tratamento adequado por parte de especialistas oriundos dos meios acadêmicos e empresarial, evitando-se o amadorismo e a improvisação que tão bem caracterizam "experts" de última hora.

Em última análise, o assunto deste artigo bem reflete o significado e a importância das necessárias e indispensáveis relações que devem existir entre universidade e empresa.

\section{NOTAS BIBLIOGRÁFICAS}

1. BACAL, Sarah S. Pressupostos do comportamento turístico. São Paulo. ECA/JSP. 1984, 251 p. (Tese de Doutorado)

2. MICHAUD, Jean-Luc. Le tourisme face à lenvironnement. Paris, PUF, 1983, p. 61-70.

3. ROBIN Hood descobre sul da Escócia. O Estado de São Paulo - Viagem. São Paulo. 24/12/91, p.5.

4. Romance de José de Alencar fala sobre a origem da cidade. O Estado de Sũo Puulo Viagem, São Paulo. 26/11/91, p.12.

5. CIDADE quer viabilizar seu potencial turístico. Shopping Nen's - Turismo. São Pau lo, 22 e 24/03/92, p.7-B.

6. BORTOLETTO. Angela. Foz do Iguaçu - Cenário para o ecoturismo. Shopping News - Turismo. São Paulo. 10 e 12/11/91. p.6-B.

7. PRONTA para a festa das tlores. Shopping New's - Turismo. São Paulo. 10 e 12/11/91, p.17-A

8. CABREÚVA, opçāo ecológica. Shopping Newss - Turismo. São Paulo, 10 E 12/1 1/91. p.23-A.

9. COLLA. Marcia. Pariquera-Açu - O turismo ecológico é a esperança. $O$ Estado de Sáo Paulo Cidades. São Paulo. 19/02/92. p.6.

10. ECOSSELVAGEM: um ramo .mais arriscado do ecoturismo. Shopping Nens - Turismo. São Paulo, 22 e 24/03/92. p.6-B.

11. COMANDATUBA. Orixás saúdam o lazer no jardim do Édem. Shopping News Turismo. São Paulo, 26 c 28/01/92. p.10-B.

12. PARA os mais selvagens. uma aventura na mata. Shopping New's - 'Turismo. São PauIo. 22 e 24/03/92. p.6-B.

13. IBITINGA. Cidade quer vialilizar potencial turístico. Shopping Ncu's - Turismo. São Paulo, 22 e 24/03/92. p.7-B.

14. MUNIZ. Elke Lopes. Diamantina faz sua estréia nas telinhas do Brasil. O Estado de Säo Paulo - Viagem. São Paulo, 07/01/92. p.12.

15. PARKER, Linda. Uma viagem invulgar pela rota do Correio. Shopping News - Turismo. São Paulo, 05 e 07/05/91. p.7-B.

16. FLÓRIDA Express.Bush Garden, a África nos E.U.A. Shopping New's - Turismo. São Paulo. 26 e 28/01/92, p.13-B.

17. PAVONE, Antonio . Nas trilhas emocionantes de Agullias Negras. Shopping News Turismo. São Paulo, 15 e 17/03/92, p.4-B. 
18. EXPLORAR cavernas revela ao visitante belezas ancestrais. Shopping Nens - Turismo. São Paulo, 22 e 24/03/92, p.5-A e 5-B.

19. SHOPPING NEWS. São Paulo, 15 e 17/03/92. p.14-B (Turismo).

20. VIEIRA. Beatriz. Acampar: uma opção de lazer e cultura para verāo. Shopping New's - Turismo. São Paulo, 15 e 17/12/91. p.5-A.

21. A ORDEM é se divertir e aprender.

10/12/91. p.21.

22. SPA também é lugar de descanso. O Estado de São Paulo - Viagem. São Paulo. 07/01/92, p.14.

23. Shopping News, Turismo, São Paulo, 15 e 17/12/91, p.22-A.

24. EQUADOR. Brasil organiza expedição às Ilhas Galápagos. O Estado de São Paulo Viagem. São Paulo, 10/12/91. p.3

25. TURISTAS podem participar de expediçōes científicas. $O$ Estado de Säo Paulo Viagem. 25/02/92, p.6.

26. MATHIESON, A \& WALL. G. Tourism: economic, physical and social impacts London, 1982, $208 \mathrm{p}$.

27. TYLLER, C. Killing the goose. Gcographycal. Oct., 1989, p.18-21 e 31.

28. COLE, David N.. Recreation ecology: what we know, what geographers can contr1bute. Professional Gcographer. v.41. n.2. p.143-78, 1989. 